\title{
La teoría de las representaciones sociales de Serge Moscovici
}

\author{
Martín Mora \\ Universidad de Guadalajara (México)
}

\section{INTRODUCCIÓN}

Hablar de la Psicologia es, de entrada, un asunto difícil debido al inevitable encuentro con una disciplina científica versátil y en construcción. Cuando se aborda lo que ha sido denominado como Psicología Social, este problema se matiza aún más por la inclusión de los elementos ideológicos de lo aparentemente subjetivo.

En este sentido, resulta interesante estudiar uno de los modelos relativamente recientes en Psicología social: las "Representaciones Sociales", de Serge Moscovici.

Si se agrega además que dicha propuesta teórica esboza un planteamiento metodológico interesante y renovador dentro del análisis del sentido común y de lo cotidiano, podrá valorarse como una explicación útil en el estudio de la construcción social de la realidad.

En este escrito se describe y analiza el modelo de las representaciones sociales desde el punto de vista del propio Moscovici, así como desde la perspectiva de investigadores que han trabajado en esta línea, procurando apuntar algunas notas acerca de la teoría como su metodología.

Se consultaron principalmente fuentes bibliográficas para estructurar de manera temática este planteamiento, mediante la síntesis mas o menos literal de diversos textos.

Basado en el trabajo de tesis de licenciatura en Psicología en la Universidad de Guadalajara, México, este documento fue escrito en colaboración con la psicóloga Martha Elba Lares Gutiérrez y puede considerarse como una introducción al pensamiento de Serge Moscovici para aquellos interesados en la investigación de las representaciones sociales, así como para quienes resulta atractiva la teoría dentro de las ciencias sociales contemporáneas.

\section{PRESENTACIÓN}

En el capítulo primero se abordan los antecedentes teóricos que estructuran el modelo de las representaciones sociales. Según Moscovici (1979), Farr $(1983,1988)$ y Herzlich (1975); son tres las influencias básicas: la Etnopsicología de Wundt; el Interaccionismo Simbólico de Mead; y el concepto de Representaciones Colectivas de Durkheim. 
Contenido en el segundo capítulo puede hallarse el desarrollo del modelo de las representaciones sociales, considerando su definición y condiciones de emergencia; su dinámica y sus dimensiones; así como las determinaciones que socialmente la generan, en la versión inicial de Moscovici.

Algunas orientaciones metodológicas para investigar las representaciones sociales se incluyen en el capítulo tercero. Se mencionan también algunas investigaciones que han tomado como fundamento a esta teoría psicosocial.

Están expuestos en el capítulo cuarto otros aspectos ligados al cuerpo teórico como son la hipótesis de la polifasia cognitiva, la relación de la representación social con otros conceptos cognitivos y las aportaciones que ha desarrollado Moscovici en años posteriores, tales como la noción de minorías activas y la de la influencia social. Además, se incluyen breves comentarios acerca de la implicación que guardan las representaciones sociales con los ámbitos de la ciencia y la ideología.

Finalmente, en el capítulo quinto se hacen algunas consideraciones resultantes de la investigación de este modelo teórico y que expresan una opinión más personal acerca de las representaciones sociales y su valor teórico-metodológico dentro de la Psicología y su pertinencia al interior del marco de la teoría social.

\section{ANTECEDENTES TEÓRICOS}

\section{Wilhelm Wundt y la Psicología como ciencia experimental y como ciencia social}

Siempre que se hace referencia a la Psicología, se consideran sus inicios a partir de la instauración de esta disciplina como ciencia experimental. El dato más conocido habla que fue en 1879 con la fundación del Instituto de Psicología en Leipzig, cuando inicia la Psicología como ciencia experimental de laboratorio, correspondiendo a Wilhelm Wundt dicho mérito.

Wundt era un pensador alemán que dictaba cátedra de filosofía en Leipzig, enfatizando en problemas psicológicos que hasta entonces eran resueltos mediante la especulación. Motivado por ese problema, se dio a la tarea de instalar un laboratorio de Psicología experimental en el que, utilizando métodos derivados en gran medida de la fisiología, trataba de abordar problemas psicológicos. De esa manera, la Psicología dejaba de ser materia de especulación dentro de la filosofía para iniciar su historia como ciencia experimental.

Conviene señalar que alrededor del proyecto del Instituto se publicaron algunas revistas bajo la dirección del propio Wundt. Entre 1873 y 1874 apareció su Grundzüge der physiologischen psychologie, que fue tomada casi como texto de la nueva ciencia psicológica que construía. Al fundarse el laboratorio de Leipzig se crea el órgano oficial de la Psicología experimental, los Philosophische Studien, que aparecen publicados entre los años de 1881 y 1904.

Atraídos por la nueva ciencia, por sus métodos y por las cátedras dictadas por Wundt, un considerable número de estudiantes del extranjero -especialmente norteamericanos- estuvo en Leipzig aprendiendo todo lo posible con el propósito de fundar laboratorios en sus respectivos países. De manera tangencial pueden mencionarse los nombres de algunos de dichos estudiantes quienes 
más tarde aportaría ideas a la incipiente Psicología: Hall, Cattell, Wolfe; Pace, Scripture, Angell; Titchener y Witmer, especialmente.

Sin embargo, según dice Robert Farr (1983), estos académicos muy probablemente no fueron sensibles a los aspectos filosóficos y culturales de la tradición alemana de la investigación y regresaron a sus países impresionados más bien por los deslumbrantes instrumentos utilizados por la Psicología experimental alemana. Miopía científica que generaría el posterior auge de la Psicología de laboratorio, individual y de tipo conductista, favorecida por el positivismo de Mach y de Avenarius y por la particular manera de interpretar la idea de Wundt por parte del gran difusor americano de esta Psicología, Titchener, y de su discípulo Boring, autor de la ya clásica obra A History of Experimental Psychology.

Las preocupaciones de Wundt no estaban totalmente ubicadas en su proyecto de Psicología experimental, sino que a la par iba construyendo modelos de explicación de otros fenómenos a los que no se respondía en su laboratorio. Señala Farr (1983) que Wundt, desde principios de 1862, el el prefacio de su Beiträge zur Theorie der Sonneswarhnemung, se propone llevar a cabo tres tareas: la creación de una Psicología experimental, de una metafísica científica y de una Psicología social.

En consecuencia, Wundt establecía una distinción entre Psicología experimental y Psicología social. Al asignarle un lugar a cada una de ellas, siguiendo la distinción básica alemana entre ciencias naturales y ciencias sociales, diferencia por un lado a la Psicología fisiológica y experimental y por el otro, a la social o etnopsicología: la völkerpsychologie.

La ciencia de laboratorio de Wundt tenía como idea metodológica central la experiencia de la persona que brindaba el reporte introspectivo, siendo necesario acudir a otras formas que dieran cuenta de fenómenos más complejos en donde el individuo no podía ser fiel testigo por su implicación en el proceso. Desprende, por tanto, una metodología apropiada para los procesos cognoscitivos superiores del hombre: la interpretación de los productos de la experiencia colectiva. Los diez volúmenes de su Völkerpsychologie, publicados entre 1900 y 1920, fueron el intento de estructurar esta tendencia.

Buscó trazar la evolución de la mente en el hombre, consciente de la importancia del lenguaje en este proceso y en su relación con el pensamiento y sus producciones. Influenciado por las observaciones de Lazarus y de Steinthal sobre los pueblos; por Herder y su noción de cultura; y por Hartmann en su idea acerca de lo inconsciente en la colectividad; Wundt siguió a Darwin en su análisis de la evolución del gesto animal para desembocar en la dirección del habla y del lenguaje humanos.

Echando mano de las versiones antropológicas a las que tenía acceso, Wundt parte del análisis de la acción humana. Debajo de ese nivel de acción deliberada y voluntaria existe un primitivo movimiento de impulso que implica expresiones afectivas espontáneas y que generan respuestas de otros individuos. Aclara Kurt Danziger (1980) que existe una respuesta mimética innata a las expresiones de otros por lo que es posible la transferencia de los estados mentales del individuo. Según Wundt, este mecanismo de "comunicación de gestos" proveía las bases indispensables de la vida social, sin la cual, los individuos humanos nunca podrían empezar a entenderse.

Esta comunicación de los gestos origina productos culturales con existencia concreta: el lenguaje, proporciona un medio para la operación de la actividad cognoscitiva superior; los mitos, surgidos de esa base dan forma a la capacidad humana para imaginar; y las costumbres, enmarcan la referencia dentro de la cual operan las opciones individuales y la voluntad. Con el tiempo, estos productos 
culturales van cambiando regular y lentamente de tal suerte que, para Wundt, la observación del proceso permitía hacer inferencias acerca de lo subyacente en la Psicología de los individuos, que pudieran contrastarse con sus hallazgos de laboratorio.

Como puede deducirse, estas aportaciones de Wundt influyeron más de lo que se supone en buena parte de los pensadores de este siglo. Robert Farr (1983) menciona entre otros a Malinowski, Saussure y Mead; a Thomas, Durkheim, Boas y Freud. Además, es observable su influencia en una amplia diversidad de ciencias sociales. Dentro de la Psicología alienta a dos vertientes fundamentales, a saber: 1) la tradición de Mead con el interaccionismo simbólico en la sociología estadounidense; y 2) a través de Durkheim, la investigación sobre representaciones sociales por parte de Moscovici.

En conclusión y siguiendo a Pablo Fernández Christlieb (s.f.a), es posible decir que, junto con Le Bon y Tarde, Wundt construye con su Psicologia de los pueblos el basamento de la Psicología social en este siglo y particularmente de la Psicologia colectiva.

\section{George Herber Mead y el interaccionismo simbólico}

Siguiendo con la incipiente teorización acerca del espacio disciplinar de la Psicologia social que Wundt inaugurara, surge un movimiento filosófico en Norteamérica con fuertes implicaciones en la pedagogía, la comunicación y la propia Psicologia: el pragmatismo. Con William James, pero más concretamente con John Dewey y George Herbert Mead, el pragmatismo se define como una filosofía de la acción.

En su crítica al modelo del arco reflejo que supone como objeto la formulación de relaciones causaefecto entre estímulos ambientales y reacciones de organismos, John Dewey propone un entredicho que busca diluir ese mecanismo causal: es la acción del propio individuo lo que determina la relevancia de los estímulos dentro del contexto delimitado de la misma acción. No es una reacción organísmica refleja sino una decisión activa la que proyecta los actos de los individuos. Con esa aportación, Dewey critica la solvencia teórica de los modelos psicológicos simplistas que aparecían como la novedad en los primeros decenios del siglo XX.

Este pragmatismo -que suele confundirse inexactamente con el utilitarismo-, intenta una superación del dualismo cartesiano, según apunta Hans Joas (1987). Al desarrollar el concepto de acción, queda transformada toda la relación entre conocimiento y realidad:

El concepto de verdad ya no expresa una correcta representación cognoscitiva de la realidad, sino un aumento del poder para actuar en relación con un entorno.(Joas, 1987 p. 118)

Esta influencia del pragmatismo en la sociología se hace más decisiva al establecerse la Escuela de Chicago, como una vía de realización de esta filosofía social, encabezada por Dewey y Mead. En este ambiente, Mead empieza a integrar en un cuerpo teórico las ideas de Royce sobre la colectividad, y las ideas de Charles S. Peirce acerca del signo, para entablar el diálogo con un concepto fundamental dentro de la Psicología social: la intersubjetividad.

George Mead basa su Psicología social en una esmerada lectura de Darwin y de la etnopsicología de Wundt, escudriñando desde el gesto animal el proceso evolutivo de la comunicación humana. Si Wundt realza el papel del lenguaje como catalizador de la relación del hombre con su colectividad y con la cultura como su producto, Mead aborda a la comunicación en esta forma de interacción. 
Inicialmente, rechaza analizar el espacio interior de los individuos planteando la pertinencia de un espacio de realidad en las mediaciones; un espacio interactivo no biológico sino social que es percibido en términos de significaciones, puesto que su materia es el símbolo. Mead toma como unidad de análisis lo que denomina el acto social. Aquí, el símbolo y su significado son propiedad de la situación interactiva, no están fuera. Cabe decir que la existencia de tal significado no implica necesariamente la consciencia del mismo, puesto que ello sólo se consigue a través de la simbolización.

El argumento básico de Mead es que en este espacio interactivo radican los símbolos y sus significados, por lo que sólo ahí puede formarse el espíritu (Mind), conformado en el proceso de la comunicación. Los individuos no existen como tales sino como la persona (Self), cuyo tamaño abarca su espacio social teniendo a la sociedad (Society) como fondo. En consecuencia, Mead enfatiza dos características de esta interacción: a) quien se comunica puede comunicarse consigo mismo, y b) esta comunicación crea la realidad.

Ampliando acerca del habla significante, Mead puntualiza:

Cuando hablamos del habla significante, queremos siempre decir que el individuo que escucha una palabra emplea, en cierto sentido, esa misma palabra con referencia a sí propio. El proceso de dirigirse a otra persona es un proceso de dirigirse también a uno mismo, y de provocar en sí la reacción que provoca en el otro. (citado en Fernández Christlieb, s.f.b p. 59)

En consecuencia, Mead coloca a la intersubjetividad dentro de lo que llama conversación interior, el pensamiento, constituido por tres interlocutores: el Yo, el Mí y el Otro:

El Yo que actúa, que se aparece, que emerge de repente y sin aviso; el Mí, que constituye el percatamiento de lo que hizo el yo; y el Otro, que es el bagaje de criterios con que cuenta el mí para evaluar los actos espontáneos de ese yo... por eso el otro de Mead es un Otro Generalizado, que corresponde a la colectividad, a la realidad social, a la comunicación en la cual el yo y el mí existen.(Fernández Christlieb, s.f.a, p. 15)

En síntesis, el mí supone asumir el punto de vista colectivo con respecto a uno mismo, y el otro generalizado es la gran colectividad con la que uno se relaciona y que tiende a ser interiorizada: la sociedad crea a los individuos. Parafraseando a Carlo Donolo (1981), puede decirse que gracias a esa "reflexividad" de la experiencia a través del lenguaje, el individuo se relaciona con su propio pasado, asume la actitud de los otros respecto a sí mismo y se integra al proceso social en forma dinámica.(cfr. Martín-Baró, 1983 pp. 123-124)

Todas esas reflexiones hechas por Mead y manejadas en sus cátedras, serían publicadas de manera póstuma (en 1934) en un libro titulado Mind, Self and Society, editado por la prensa de la Universidad de Chicago y bautizadas por Herbert Blummer como interaccionismo simbólico.

A manera de recapitulación, pueden acotarse las aportaciones más significativas de Mead a las ciencias sociales, incluyendo a la Psicología:

a) Enfatiza la noción de una realidad simbólica distinta de una probable realidad natural; susceptible de creación, de transformación y de destrucción.

b) Anticipa la visión epistemológica que cuestiona lo que es o no científico por medio del consenso significativo y el criterio de objetividad científica como una construcción simbólica. 
c) Su análisis de la sociedad contempla la posibilidad de la incorporación total del individuo a un universo de razón, actividad consciente y voluntaria, hacia una esfera pública no restrictiva (v.g. los teóricos de la Escuela de Frankfurt y de la teoría crítica, como Habermas).

d) La naturaleza social del lenguaje y la naturaleza simbólica de la sociedad, dejan de ser objeto de especulación filosófica haciéndose accesibles al análisis empírico.

Las lagunas que George Mead dejó dentro de sus supuestos teóricos, han dado pie a muy diversas disciplinas: sociología fenomenológica del conocimiento (Schutz, Berger y Luckmann); etnometodología (Garfinkel); teoría de las representaciones sociales (Moscovici). Tal y como Berger y Luckmann (1967) han señalado al referirse a su deuda teórica con Mead, eslabonar esta sociología del conocimiento sugiere la posibilidad de la existencia de una Psicología sociológica, es decir, una Psicología social con perspectiva sociológica y una notoria preocupación por lo simbólico, por su papel en lo colectivo y por la construcción social de la realidad.

\section{3. Émile Durkheim y el concepto de representación colectiva}

Émile Durkheim, uno de los fundadores de la sociología científica, visitó entre 1885 y 1886 varias universidades alemanas, entre las cuales se encontraba la de Leipzig donde Wundt dictaba sus cátedras y tenía su laboratorio de Psicología experimental. El rigor con que Wundt realizaba sus experimentos, así como el hecho de que contara con una publicación oficial de su propio laboratorio, fueron motivos para que Durkheim se mostrara interesado en esas propuestas tanto de la Psicología experimental como de la etnopsicología.

Al igual que Wundt, Durkheim (1898) estableció diferencias entre las representaciones individuales y las representaciones colectivas, explicando que lo colectivo no podía ser reducido a lo individual. Es decir, que la conciencia colectiva trasciende a los individuos como una fuerza coactiva y que puede ser visualizada en los mitos, la religión, las creencias y demás productos culturales colectivos. Al respecto, Ignacio Martín-Baró señala:

Una sociedad mantiene su unidad debido a la existencia de una conciencia colectiva. La conciencia colectiva consiste en un saber normativo, común a los miembros de una sociedad e irreductible a la conciencia de los individuos, ya que constituye un hecho social. (Martín- Baró, 1985 p. 33)

Fundamentado en su visión teórica, Durkheim se atreve a hacer la diferencia entre sociología y Psicología: a la primera le correspondía analizar todo acerca de las representaciones colectivas y a la segunda lo propio de las representaciones individuales. En consecuencia, Durkheim (1895) definía el campo de la Psicología social argumentando que debía estudiar cómo las representaciones sociales se llaman y se excluyen, se fusionan o se hacen distintas unas de otras. Sin embargo, estrecha el ámbito de estudio de la Psicología poniendo en la mira de la sociología una buena cantidad de fenómenos que atañían más a una especie de Psicología social o colectiva.

Tuvieron que pasar varias décadas para que Serge Moscovici retomara estos planteamientos y desarrollara una teoría en Psicología social con marcada tendencia sociológica cuando el común denominador de las investigaciones en Psicología era lo individual, por la influencia norteamericana. Con su teoría de las representaciones sociales, Moscovici integra en una Psicología social las aportaciones de diversas disciplinas, dentro de un contexto europeo de rápida expansión. 


\section{EL MODELO DE SERGE MOSCOVICI}

\section{Definición del concepto de representación social}

Con respecto a las representaciones sociales, Serge Moscovici ha señalado en El psicoanálisis, su imagen y su público, las siguientes consideraciones:

La representación social es una modalidad particular del conocimiento, cuya función es la elaboración de los comportamientos y la comunicación entre los individuos. La representación es un corpus organizado de conocimientos y una de las actividades psíquicas gracias a las cuales los hombres hacen inteligible la realidad física y social, se integran en un grupo o en una relación cotidiana de intercambios, liberan los poderes de su imaginación. (Moscovici, 1979 pp. 17-18)

Dicho en términos más llanos, es el conocimiento de sentido común que tiene como objetivos comunicar, estar al día y sentirse dentro del ambiente social, y que se origina en el intercambio de comunicaciones del grupo social. Es una forma de conocimiento a través de la cual quien conoce se coloca dentro de lo que conoce. Al tener la representación social dos caras -la figurativa y la simbólica- es posible atribuir a toda figura un sentido y a todo sentido una figura.

Por otra parte, Denise Jodelet, estudiosa que se ha interesado también por el tema de las representaciones sociales ha dicho que el campo de representación designa al saber de sentido común, cuyos contenidos hacen manifiesta la operación de ciertos procesos generativos y funcionales con carácter social. Por lo tanto, se hace alusión a una forma de pensamiento social.

Uno de quienes más ha estudiado la teoría de Moscovici y que ha indagado acerca de sus antecedentes teóricos es Robert Farr, quien ofrece su versión de la noción de representaciones sociales señalando que, desde una perspectiva esquemática, aparecen las representaciones sociales cuando los individuos debaten temas de interés mutuo o cuando existe el eco de los acontecimientos seleccionados como significativos o dignos de interés por quienes tienen el control de los medios de comunicación. Agrega además que las representaciones sociales tienen una doble función: "hacer que lo extraño resulte familiar y lo invisible perceptible", ya que lo insólito o lo desconocido son amenazantes cuando no se tiene una categoría para clasificarlos. Parafraseando a Moscovici, Farr escribe una definición sumaria de las representaciones sociales:

Sistemas cognoscitivos con una lógica y un lenguaje propios. No representan simplemente opiniones acerca de, "imágenes de", o "actitudes hacia" sino "teorías o ramas del conocimiento" con derechos propios para el descubrimiento y la organización de la realidad. Sistemas de valores, ideas y prácticas con una función doble: primero, establecer un orden que permita a los individuos orientarse en su mundo material y social y dominarlo; segundo, posibilitar la comunicación entre los miembros de una comunidad proporcionándoles un código para el intercambio social y un código para nombrar y clasificar sin ambigüedades los diversos aspectos de su mundo y de su historia individual y grupal. (Farr, 1983 p. 655)

María Auxiliadora Banchs es otra de las investigadoras que ha trabajado sobre esta temática y apuntado con respecto a las representaciones sociales su propia definición, en la que remarca el doble carácter de éstas como contenido y como proceso: en tanto que una particular forma de conocimiento y también una estrategia de adquisición y comunicación del mismo conocimiento. Por lo tanto, son una forma de reconstrucción mental de la realidad generada en el intercambio de 
informaciones entre sujetos. Aprovechando estos indicadores, Banchs (1984) elabora una interpretación de la idea de representación social, mostrándola como una forma del conocimiento de sentido común que caracteriza a las sociedades modernas "bombardeadas" de manera constante por la información que los medios de comunicación divulgan. Siguen, por tanto, una lógica propia que es diferente, pero no inferior, a la lógica científica y que encuentran su expresión en un lenguaje cotidiano propio de cada grupo social.

Es posible encontrar otras exposiciones acerca de lo que son las representaciones sociales en autores como Di Giacomo (1987) quien resalta su papel práctico en la regulación de los comportamientos intra e intergrupales; y Páez (1987) quien las observa como una expresión del pensamiento natural, no formalizado ni institucionalizado. En Acosta y Uribe (s.f.), se alude a la doble modalidad de la representación social. Por un lado como modo de conocimiento, es decir, como actividad de reproducción de las características de un objeto; de su reconstrucción mental. Por el otro como una forma de pensamiento social que estructura la comunicación y las conductas de los miembros de un grupo.

Finalmente, el propio Darío Páez ofrece una caracterización de las representaciones sociales en un esquema sintético que habla de las funciones que cumplen como forma de pensamiento natural. Cuatro son las características esenciales:

1) Privilegiar, seleccionar y retener algunos hechos relevantes del discurso ideológico concernientes a la relación sujeto en interacción, o sea descontextualizar algunos rasgos de este discurso.

2) Descomponer este conjunto de rasgos en categorías simples naturalizando y objetivando los conceptos del discurso ideológico referente al sujeto en grupo.

3) Construir un 'mini-modelo' o teoría implícita, explicativa y evaluativa del entorno a partir del discurso ideológico que impregna al sujeto.

4) El proceso reconstruye y reproduce la realidad otorgándole un sentido y procura una guía operacional para la vida social, para la resolución de los problemas y conflictos. (Páez, 1987 pp. 316317)

\section{Condiciones de emergencia de una representación social}

Según Moscovici, las representaciones sociales emergen determinadas por las condiciones en que son pensadas y constituidas, teniendo como denominador el hecho de surgir en momentos de crisis y conflictos. De manera convergente, Tajfel propone que las representaciones sociales requieren responder a tres necesidades: a) clasificar y comprender acontecimientos complejos y dolorosos; b) justificar acciones planeadas o cometidas contra otros grupos; y c) para diferenciar un grupo respecto de los demás existentes, en momentos en que pareciera desvanecerse esa distinción. En suma, causalidad, justificación y diferenciación social. (cfr. Páez, 1987 p. 300)

A raíz de las comprobaciones hechas en su investigación, Moscovici infiere tres condiciones de emergencia: la dispersión de la información, la focalización del sujeto individual y colectivo y la presión a la inferencia del objeto socialmente definido.

a) Dispersión de la información. Según Moscovici, la información que se tiene nunca es suficiente y por lo regular está desorganizada: 
Los datos de que disponen la mayor parte de las personas para responder a una pregunta, para formar una idea a propósito de un objeto preciso, son generalmente, a la vez, insuficientes y superabundantes (Moscovici, 1979 pp. 176-177)

Por su parte, la diversidad de autores que han trabajado en esta teoría, interpretan la noción de variadas formas aunque predomina el hecho de que se considera que hay desniveles en cantidad y calidad de la información al interior de un grupo, y parcialidad y desfase en relación con lo requerido para constituir el fundamento sólido del conocimiento. Es decir, nunca se posee toda la información necesaria o existente acerca de un objeto social que resulte relevante.

Moscovici (1979) concluye afirmando que la multiplicidad y desigualdad cualitativa entre las fuentes de información con relación a la cantidad de campos de interés, vuelven precarios los vínculos entre los juicios y, por ende, compleja la tarea de buscar todas las informaciones y relacionarlas.

b) Focalización. Una persona o una colectividad -dice Moscovici (1979)- se focalizan porque están implicadas en la interacción social como hechos que conmueven los juicios o las opiniones. Aparecen como fenómenos a los que se debe mira detenidamente.

En palabras de otros investigadores como Banchs $(1984,1990)$ y Herzlich (1979), la focalización es señalada en términos de implicación o atractivo social de acuerdo a los intereses particulares que se mueven dentro del individuo inscrito en los grupos de pertenencia. La focalización será diversa y casi siempre excluyente.

c) Presión a la inferencia. Socialmente se da una presión que reclama opiniones, posturas y acciones acerca de los hechos que están focalizados por el interés público:

En la vida corriente, las circunstancias y las relaciones sociales exigen del individuo o del grupo social que sean capaces, en todo momento, de estar en situación de responder. (Moscovici, 1979 p. 178)

Para Banchs (1984) las exigencias grupales para el conocimiento de determinado evento u objeto se incrementan a medida que su relevancia crezca. El propósito crucial es no quedar excluido del ámbito de las conversaciones sino poder realizar inferencias rápidas, opiniones al respecto y un discurso más o menos desarrollado.

Citando a Moscovici, Claudine Herzlich (1979) anota que las exigencias sobre el individuo o grupo social que las circunstancias y las relaciones sociales imponen, provocan una actuación, una estimación o una comunicación. "Las informaciones deben llegar a ser, sin dilación, fundamento de conducta, instrumento de orientación" (p. 397).

Según María Auxiliadora Banchs (1990), la presión a la inferencia quiere describir un hecho significativo en la dinámica colectiva que alude al hecho de que frecuentemente existe la obligación de emitir opiniones, sacar conclusiones o fijar posiciones respecto a temas controversiales, considerados de actualidad en los círculos sociales de pertenencia.

Estas tres condiciones de emergencia -dispersión de la información, grado de focalización y presión a la inferencia- constituyen el pivote que permite la aparición del proceso de formación de una representación social $\mathrm{y}$, en mayor o menor grado, al conjuntarse hacen posible la génesis del esquema de la representación. El común denominador de esta relación sería la traducción de la disparidad de posiciones frente a un objeto significativo en términos sociales y recuperado de un contexto dinámico, cambiante y conflictivo. Con el movimiento de tales condiciones de emergencia 
quedaría determinada tanto la naturaleza de la organización cognoscitiva de la representación, es decir, su estructuración como esquema cognoscitivo; así como su misma existencia y grado de estructuración.

\section{Dimensiones de la representación social}

Las representaciones sociales definidas por Moscovici como "universos de opinión", pueden ser analizadas con fines didácticos y empíricos en tres dimensiones: la información, el campo de representación y la actitud.

a) La información. Es la organización o suma de conocimientos con que cuenta un grupo acerca de un acontecimiento, hecho o fenómeno de naturaleza social. Conocimientos que muestran particularidades en cuanto a cantidad y a calidad de los mismos; carácter estereotipado o difundido sin soporte explícito; trivialidad u originalidad en su caso:

Dimensión o concepto, se relaciona con la organización de los conocimientos que posee un grupo respecto a un objeto social. (Moscovici, 1979 p. 45)

Por lo tanto, esta dimensión conduce necesariamente a la riqueza de datos o explicaciones que sobre la realidad se forman los individuos en sus relaciones cotidianas.

b) El campo de representación. Expresa la organización del contenido de la representación en forma jerarquizada, variando de grupo a grupo e inclusive al interior del mismo grupo. Permite visualizar el carácter del contenido, las propiedades cualitativa o imaginativas, en un campo que integra informaciones en un nuevo nivel de organización en relación a sus fuentes inmediatas:

Nos remite a la idea de imagen, de modelo social, al contenido concreto y limitado de las proposiciones que se refieren a un aspecto preciso del objeto de representación. (ibid., 1979 p. 46)

Banchs (1984) hace suya la definición de Moscovici aunque agrega que "debe analizarse en función de la totalidad del discurso sobre un objeto y no sólo en un párrafo o en una frase" (p. 9). Enfatiza así el carácter global del campo de representación y la dificultad metodológica para abarcarlo (problema siempre presente en las investigaciones que hemos analizado y que dicen utilizar este modelo teórico). Además, según Herzlich (1979), deben considerarse los factores ideológicos en la estructuración del campo de representación.

c) La actitud. Es la dimensión que significa la orientación favorable o desfavorable en relación con el objeto de la representación social. Se puede considerar, por lo tanto, como el componente más aparente, fáctico y conductual de la representación, y como la dimensión que suele resultar más generosamente estudiada por su implicación comportamental y de motivación.

Si bien esta clasificación no sustenta ninguna jerarquía o prioridad, el propio Moscovici lanza la hipótesis de su cronología que, al verse en conjunto, completa la estructura de la representación en términos de contenido y de sentido. Señala Moscovici:

Se deduce que la actitud es la más frecuente de las tres dimensiones y, quizá, primera desde el punto de vista genético. En consecuencia, es razonable concluir que nos informamos y nos representamos una cosa únicamente después de haber tomado posición y en función de la posición tomada. (Moscovici, 1979 p. 49) 
Si la actitud significa una especie de componente motivacional afectivo en la conformación de una representación social, resulta pertinente la observación de Herzlich (1979) respecto a hacer estudios comparativos sobre la fisura o diferencia de los grupos en función de sus representaciones sociales, ya que éstas contribuyen a definir con cierta precisión tanto a los grupos como a sus tendencias.

\section{Dinámica de una representación social}

La investigación de Moscovici buscaba estudiar el proceso de penetración de una ciencia -el psicoanálisis- en la sociedad francesa de los años cincuenta. Pudo distinguir dos procesos básicos que explican cómo lo social transforma un conocimiento en representación colectiva y cómo ésta misma modifica lo social: la objetivación y el anclaje.

Estos conceptos se refieren a la elaboración y al funcionamiento de una representación social mostrando la interdependencia entre lo psicológico y los condicionantes sociales, así como su difícil esclarecimiento en términos exhaustivos. Sin embargo, Moscovici esboza este proceso evitando en lo posible su inapropiada descomposición o la simplicidad. Con esta advertencia, puede esquematizarse en los siguientes trazos.

a) Objetivación: selección y descontextualización de los elementos, formación del núcleo figurativo y naturalización. El proceso de objetivación va desde la selección y descontextualización de los elementos hasta formar un núcleo figurativo que se naturaliza enseguida. Es decir, lo abstracto como suma de elementos descontextualizados debe tornarse una imagen más o menos consistente en la que los aspectos metafóricos ayuden a identificarla con mayor nitidez. Se constituye así un edificio teórico esquematizado.

La objetivación lleva a hacer real un esquema conceptual, a duplicar una imagen con una contrapartida material. El resultado, en primer lugar, tiene una instancia cognoscitiva: la provisión de índices y de significantes que una persona recibe, emite y toma en el ciclo de las infracomunicaciones, puede ser superabundante. Para reducir la separación entre la masa de las palabras que circulan y los objetos que las acompañan (...) los 'signos lingüísticos' se enganchan a 'estructuras materiales' (se trata de acoplar la palabra a la cosa). (Moscovici, 1979 p. 75)

El modelo figurativo o esquema que resulta, cumple muchas funciones: a) constituye punto común o mediador entre la teoría científica inicial y su representación social; b) aquí se realiza el cambio de lo que en la teoría es exposición general, abstracta e indirecta de una serie de fenómenos, en una traducción inmediata y funcional de la realidad que sirve al hombre común y corriente; c) el modelo asocia diversos elementos en un foco explicativo con una dinámica propia y suficiente; y d) permite a la representación social convertirse en un marco cognoscitivo estable y orientar tanto las percepciones o los juicios sobre el comportamiento, como las relaciones interindividuales.

En un primer momento, la concepción científica se confronta con el sistema de valores sociales resultando una elección de entre sus elementos. La naturalización otorga a la representación social el carácter de evidencia válida: se convierte en una "teoría profana" autónoma que sirve para categorizar las personas y sus comportamientos.

Moscovici concluye con su análisis de la objetivación apuntando hacia la realización del objeto de representación en sus nexos con los valores, la ideología y los parámetros de la realidad social. La actividad discriminativa y estructurante que se va dando por medio de la objetivación, se explica precisamente por sus tintes normativos: la representación social adquiere una armazón de valores. 
En estas combinaciones incipientes de experiencias y estructuras simbólicas puede percibirse un realismo semejante al de los niños que dibujan no sólo lo que ven de un objeto, sino también lo que saben de él. La imagen es objetivada junto con una carga de afectos, valores y condiciones de naturalidad. Los conceptos así naturalizados se transforman en auténticas categorías del lenguaje y del entendimiento.

Como puede apreciarse, Moscovici (1979) presenta un análisis complejo y sistemático del proceso de objetivación que, en muchos casos, parece denso pero que se explica por esa preocupación constante para no desarticular inapropiadamente un fenómeno global que no sigue una secuencia rígida ni causal. De igual manera, tanto Jodelet (1984), como Herzlich (1979) y Banchs (1984), señalan que la importancia de un proceso como el de la objetivación reside en que pone a disposición del público una imagen o esquema concreto, a partir de un ente abstracto o poco tangible como lo es una teoría o concepción científica.

Para concluir con la objetivación de una representación social, conviene recordar que todas las definiciones intentan explicar el paso de un conocimiento científico al dominio público (el psicoanálisis, en la investigación de Moscovici), y que el segundo proceso de formación de una representación social -el anclaje- se liga al primero en forma natural y dinámica.

b) Anclaje. Con el anclaje la representación social se liga con el marco de referencia de la colectividad y es un instrumento útil para interpretar la realidad y actuar sobre ella.

Designa la inserción de una ciencia en la jerarquía de los valores y entre las operaciones realizadas por la sociedad. En otros términos, a través del proceso de anclaje, la sociedad cambia el objeto social por un instrumento del cual puede disponer, y este objeto se coloca en una escala de preferencia en las relaciones sociales existentes. (Moscovici, 1979 p. 121)

Al insertarse el esquema objetivado dentro de una red de significaciones, la representación social adquiere una funcionalidad reguladora de la interacción grupal, una relación global con los demás conocimientos del universo simbólico popular. Las figuras del núcleo de la representación son teñidas de significados que permiten utilizar a la representación como un sistema interpretativo que guía la conducta colectiva. Además, el anclaje implica la integración cognitiva del objeto de representación dentro del sistema preexistente del pensamiento y sus respectivas transformaciones. Se trata, en suma, de su inserción orgánica dentro de un pensamiento constituido. Señala Denise Jodelet (1984), que el anclaje genera conclusiones rápidas sobre la conformidad y la desviación de la nueva información con respecto al modelo existente y proporciona marcos ideológicamente constituidos para integrar la representación y sus funciones.

De manera sintética, Moscovici (1979) aclara ambos procesos argumentando que la objetivación traslada la ciencia al dominio del ser y que el anclaje la delimita en el de el hacer (p. 121); así como la objetivación presenta cómo los elementos de la ciencia se articulan en una realidad social, el anclaje hace visible la manera en que contribuyen a modelar las relaciones sociales y también cómo se expresan.

\section{Determinación de una representación social}

Además de las dimensiones, de la dinámica y de las condiciones de emergencia de una representación social, existen formas de determinación social: la central y la lateral. Estas han sido 
nombradas por Moscovici en trabajos posteriores a su estudio sobre el psicoanálisis, e incluidos por sus epígonos en reflexiones sobre la teoría.

En el caso de Herzlich, encontramos diferenciadas dichas determinaciones que buscan responder a la pregunta que se hace respecto a la forma en que la estructura social determina los aspectos de una representación. Comenta Herzlich (1979) que también Moscovici propone distinguir a la determinación social central que regularía el surgimiento de la representación y su contenido, de la determinación social lateral, menos directa y dirigida hacia aspectos propiamente cognoscitivos y expresivos. Agrega que debe entenderse por un lado la determinación que produce la totalidad de las circunstancias y por el otro una orientación más psicológica, combinación de experiencias y factores motivacionales. Se expresa así la manera como el individuo toma conciencia y responde socialmente.

Banchs (1984) conceptualiza a sendas determinaciones puntualizando que la influencia de las condiciones socioeconómicas e históricas de una sociedad aluden a la determinación social central; mientras que la huella del individuo, su aporte como sujeto de una colectividad se traduce en la determinación social lateral. La importancia de la distinción estriba en que permite clarificar los papeles que tanto la sociedad como el individuo juegan en la construcción de las representaciones sociales. Como la misma Banchs expone:

La determinación lateral cobra importancia en la medida en que aumenta el grado de democracia y de movilidad dentro de una sociedad; mientras que la determinación central adquiere mayor relevancia en la medida en que aumenta el grado de totalitarismo e inmovilidad dentro de una sociedad. (Banchs, 1984 p. 12)

\section{ORIENTACIONES METODOLÓGICAS PARA EL ESTUDIO DE LAS REPRESENTACIONES SOCIALES}

En su investigación sobre la penetración del psicoanálisis en la sociedad francesa, Serge Moscovici utilizó algunos procedimientos metodológicos que consideraba convenientes para su objeto de estudio. Empleó cuestionarios estructurados y semiestructurados aplicados en distintas muestras de la población así como un minucioso análisis de contenido de todos los artículos relacionados con el psicoanálisis aparecidos en periódicos, revistas y diarios entre el 11 de enero de 1952 y el 11 de marzo de 1953. Los resultados fueron publicados en el libro La Psychanalyse, son image et son public, el año de 1961.

Cabe aclarar que Moscovici no recomendó ningún método en particular sino que sugirió la utilización de las técnicas que abarcaran las dimensiones que constituyen una representación social. Dice Moscovici :

Los sondeos no son un medio adecuado para evaluar el impacto de la ciencia en la opinión pública (...) Para comprender el impacto de la difusión de los conocimientos científicos y tecnológicos, y los trastornos que esto produce a niveles lingüísticos, intelectuales, culturales, simbólicos, se requieren otros métodos que los empleados normalmente y otros enfoques teóricos. (Moscovici, 1963, citado en Farr, 1986 p. 505)

Usar entrevistas abiertas o en profundidad, la observación participante de tendencias etnológicas o el análisis minucioso del lenguaje de los individuos, son algunas de las técnicas para la recolección y el 
análisis de la información que permiten develar las contradicciones que ocultan a la ideología. De igual manera, las preguntas proyectivas de frases incompletas le han permitido a Banchs el estudio de las contradicciones internas en los entrevistados.

En su estudio sobre las representaciones sociales como una alternativa teórica para la Psicología social en Latinoamérica, María Auxiliadora Banchs (s.f.) reseña en forma breve tres técnicas de análisis que han sido utilizadas: análisis de procedencia de la información, análisis de los actos ilocutorios y análisis gráfico de los significantes. Con la advertencia respecto a la existencia de otras muchas técnicas de análisis empleadas en el tratamiento de las representaciones sociales, las describimos siguiendo muy de cerca a Banchs.

\section{Análisis de procedencia de la información (Jodelet)}

La autora ideó esta técnica para analizar independientemente del contenido temático, las fuentes de información de las cuales el sujeto obtenía sus datos. Al estudiar la representación social del cuerpo humano (1976), encontró cuatro fuentes globales de procedencia de la información extendidas desde lo más personal hasta lo más impersonal: la vivencia del propio sujeto, lo que piensa el sujeto sobre sí, lo adquirido a través de la comunicación social y la observación (refranes y creencias populares), y los conocimientos adquiridos a través de los medios más bien formales como estudios, lecturas, profesión.

Distinguir entre un contenido y una fuente de procedencia de información requiere de un criterio establecido y presenta un alto grado de dificultad. Sin embargo, es una técnica muy valiosa porque al reflejar la distancia que el sujeto toma frente al objeto de conocimiento permite discriminar el grado de implicación personal y el arraigo social de dicho conocimiento.

\section{Análisis de los actos ilocutorios (Flahault)}

Es una técnica que analiza los diálogos recogidos en textos, medios de comunicación o en observaciones. Se buscan detectar los actos explícitos como órdenes o peticiones que definen la relación existente entre los interlocutores, así como los actos implícitos que claramente señalan las posiciones respectivas entre los interlocutores. Se analizan las relaciones de poder, las reglas explícitas e implícitas, la dureza actitudinal de la representación social. De alguna manera se establece una fotografía de los actos de poder, sugestión o intercambio a través del lenguaje y, sobre todo, de sus usos.

\section{Análisis gráfico de los significantes (Friedman)}

Los materiales grabados son transcritos y enumeradas las unidades de significación (en general, sujeto y predicado) de acuerdo con su orden de aparición en el discurso y se identifican las palabras que más se repiten. Por último, se reproducen gráficamente cono en un sociograma todas las palabras señalando por medio de flechas la relación que tenían en el discurso original. Se trata de conseguir la forma gráfica más ilustrativa de las relaciones entre las palabras: núcleos de pensamiento equivalentes a lo que Moscovici llama el núcleo figurativo.

Debido a su laboriosidad es un método recomendado en investigaciones con un número reducido de sujetos de prueba. Su ventaja está en que no fragmenta el discurso y, como señala Banchs, el uso de categorías lógicas sigue teniendo la ventaja de hacer surgir los núcleos de estructuración de las 
representaciones del propio discurso de los sujetos, sin la mediación del investigador. Aunque el estilo de este trabajo se basa en la exposición que hacen distintos autores, quisiéramos señalar, sin mayores intenciones polémicas, que vemos dicha afirmación con gran reserva y escepticismo.

De igual manera, Tomás Ibáñez (1988) ha descrito una de las intervenciones metodológicas más frecuentemente usadas en la investigación de las representaciones sociales:

\section{Análisis de correspondencias (Di Giacomo)}

Se trata de un análisis multidimensional de tipo factorial que presenta un alcance eminentemente descriptivo. Basándose en el diferencial semántico, se selecciona una serie de palabras-estímulo que aluden al objeto social a indagar. Se pide a una muestra de sujetos que efectúe una asociación libre a partir de cada palabra hasta desembocar en una especie de "diccionario de asociaciones" o algo parecido a los "campos semánticos" (en realidad se trata, según lbáñez, de "campos lexicales"). Estos datos ayudan a la construcción de la dimensión información de la representación. Lo siguiente consiste en recurrir al análisis de correspondencias para establecer el grado de similitud que existe entre los diversos campos semánticos y así generar unas representaciones gráficas en donde es posible visualizar el grado de solapamiento o de independencia entre los campos, según sea la zona gráfica de aglutinamiento. Lo conveniente, como en cualquiera de las vías metodológicas, es complementarla con otros métodos que permitan una perspectiva dinámica y no sólo una fotografía de la representación o una mera tipología.

Por su parte, Di Giacomo (1987) hace consideraciones sobre el problema de la metodología y lo que a su juicio debe orientar los estudios: los procesos antes que los contenidos en sí. Además, señala tres criterios para identificar a una representación social: que esté estructurada, que comparta elementos emocionales con el nuevo elemento que la reactiva y que el conjunto de opiniones esté unido a comportamientos específicos. En consecuencia, Di Giacomo extrae algunas conclusiones metodológicas:

1) no se puede prejuzgar sobre la extensión posible del campo figurativo del objeto; 2) las representaciones mismas son las que guían para reconocer a grupos ideológicos diferentes o antagónicos; 3) debe disponerse de métodos que hagan visible la estructura de opiniones en un sistema más o menos definido; 4) toda investigación acerca de las representaciones sociales debe contar con criterios establecidos relativos a la existencia y consistencia de la representación, con el fin de poder enmarcarla y analizarla; y 5) deben existir criterios mínimos: la relación de los aspectos emotivos y actitudinales y la capacidad del modelo para integrar nuevos elementos (carácter modélico), y la relación entre los comportamientos (carácter funcional).

En otro sentido de análisis, Jodelet (1984) señala que a medida que fue precisándose como teoría, en las representaciones sociales se han delimitado campos de investigación con ópticas diferentes. EI énfasis en cada una de ellas está en la manera de formular cómo se elabora la construcción psicológica y social de la representación.

La primera perspectiva, se limita a la actividad cognitiva con la que el sujeto construye su representación. En la segunda óptica, se considera que el sujeto es un "productor de sentido", por lo que se acentúan los aspectos significantes de la actividad representativa. El tercer enfoque trata a la representación como una forma de discurso y obtiene sus características de la práctica discursiva de sujetos en la sociedad. La cuarta visión, considera la práctica social del sujeto en tanto que derivada 
de las ideologías o posiciones relacionadas con el lugar que ocupa en la sociedad. Para la quinta corriente, es el juego de las relaciones intergrupales el que determina la dinámica de las representaciones. En la sexta perspectiva, más sociologizante, convierte al sujeto en portador de determinaciones sociales y de visiones estructuradas por las ideologías dominantes (cfr. Jodelet, 1984 pp. 479-480). Estas visiones suelen coincidir y plantearse idénticos problemas, aunque con matices, de tal suerte que abordan la doble cuestión que se halla en la base de la teoría: cómo lo social interviene en la elaboración psicológica de la representación social y cómo influye ésta construcción psicológica en lo social.

La misma Jodelet, hace la distinción y ubicación de los distintos investigadores de la teoría y encuentra sectores clave de aplicación, en la comunicación social, la difusión y asimilación de conocimientos, en el campo educativo, en la genética de las representaciones, la formación de distintas concepciones sobre la realidad dentro de un grupo, entre otras. En cualquier caso, no debiera olvidarse que las directrices metodológicas marchan de la mano de los objetos estudiados y de las creencias asumidas por los mismos investigadores. Conviene mantener en un punto de discusión algunas de las críticas que se han hecho al modelo de las representaciones sociales y que según Ibáñez (1988) a veces son escamoteadas: la función mistificadora del concepto de representación social, las falacias conceptuales del modelo de las representaciones y la inadecuación metodológica.

Finalmente, para ilustrar la amplia gama de investigaciones sobre las representaciones sociales, se anotan algunos de los temas que tenemos conocimiento de que han sido abordados: la salud y la enfermedad (Herzlich, 1969 Y 1973); el cuerpo humano y la enfermedad mental (Jodelet, 1983); la infancia (Chombart de Lauwe, 1971 y 1978); contacto con la cultura francesa de estudiantes venezolanos (Banchs, 1982); la deuda externa (Dobles y otros, s.f.c.). Como tesis de grado: la locura (Duarte y Rodríguez, 1983); la depresión (Espinoza y Topetta, 1983); el feminismo (Espina y Patiño, 1984); la maternidad (Lomely, 1984); los valores transmitidos por los medios masivos de comunicación (Gómez y Chacón, 1984); el cuerpo de los alumnos visto por las maestras (Gutiérrez y Salazar, 1984); la Psicología social (Banchs, 1984 y 1985) el cuerpo (Miguez y Villegas, 1984); el rol de la mujer (Gómez y Velazco, 1984); la pareja (Valencia, 1995). Asimismo, se tiene conocimiento acerca de investigadores que trabajan en temas diversos tanto de las representaciones sociales como sobre conducta moral, construccionismo social, Psicología colectiva y conocimiento cotidiano, quienes integran la Social Representations Comunication Network, con sede en el Institut für Psychologie de la Universität Linz en Austria.

\section{ELABORACIONES ALREDEDOR DEL MODELO DE SERGE MOSCOVICI}

\section{La hipótesis de la polifasia cognitiva}

Moscovici encuentra en la base de la forma de pensamiento que estudia en su investigación, dos principios que correlaciona con aspectos de la representación social: la analogía y la compensación.

a) la analogía, corresponde a la agrupación de nociones en una misma categoría, a la génesis de un nuevo contenido; b) la compensación, se refiere a la organización de las relaciones entre los juicios. 
La analogía contribuye a fundar las características representadas del objeto, es decir, se centra en el objeto; y la compensación edifica las significaciones y enlaces que le corresponden, esto es, con el marco de referencia que controla y guía el razonamiento.

Asimismo, Moscovici se topa con interesantes aspectos en la génesis del sentido común y su utilización como guía de conducta social. Señala tres observaciones que le hicieron detenerse con el fin de sugerir algunas propuestas útiles para una Psicología social del conocimiento: la primera, es la similitud entre la forma de pensamiento descrita en su libro y la que caracteriza a la inteligencia concreta; la segunda, es el parentesco que une a la analogía y la compensación con el sincretismo infantil; y la tercera observación es la de que coexisten en el individuo varios modos de pensamiento.

Para Moscovici, en la Psicología genética existe un estrecho paralelismo entre socialización y sucesión cronológica. Entonces, es posible hablar de escalas de socialización y de estructuras intelectuales superiores a otras puesto que puede definirse lo que se entiende por socialización. Sin embargo, cuando se analizan situaciones globales, los criterios muestran su insuficiencia y la Psicología social no tiene posibilidad de recurrir a un paralelismo análogo al de la Psicología genética. En consecuencia, Moscovici observa un fenómeno que la Psicología genética de Piaget no explica con suficiencia:

Una vez que ha dominado el universo físico e ideológico, el niño, el adolescente, están muy lejos de llegar a un empleo general de su instrumento intelectual. Por otra parte, la sociedad no se lo pide. La capacidad de hacerlo no está asegurada (...) la coexistencia de diversos sistemas cognitivos se convierte más en la regla que en la excepción (Moscovici, 1979 p. 201).

Los mismos individuos o grupos, son capaces de emplear lógicas variables de acuerdo a los distintos dominios de su actividad. Registros lógicos que dependen, según dice Moscovici, del grado de dominio y profundidad del medio ambiente objetivo, de la naturaleza de las comunicaciones, las acciones y resultados buscados y de la interacción entre colectividad y medio social físico. Visto de manera global, se puede estimar la coexistencia de modos distintos del conocimiento que corresponden a relaciones definidas del hombre y de su medio: un estado de polifasia cognitiva.

Al entender que génesis y evolución cronológica no deben confundirse, Moscovici (1979) sugiere dos vías de estudio: la primera, sería la de analizar las correspondencias entre situación social y modalidades de conocimiento; y la segunda, partiendo de la hipótesis de la polifasia cognitiva, llevaría al estudio de la transformación de esas modalidades de conocimiento, las relaciones que se establecen entre ellas y su adaptación. La polifasia cognitiva pareció ser uno de los hallazgos más estimulantes para Moscovici y sus colaboradores, por lo que señalaba que convenía ocuparse del tema en algunas de las investigaciones, hecho que ha sido explorado por la escuela suiza de las representaciones y la cognición social con Gabriel Mugny y Willem Doise a la cabeza.

\section{La representación social y otros conceptos cognitivos}

Uno de los temas en que coincide la mayoría de los estudiosos de las representaciones sociales es el de la necesidad de clarificarlas y distinguirlas de otros conceptos cognitivos que suelen ser confundidos o utilizados como sinónimos en forma inexacta. En primer lugar, conviene enfatizar el aspecto social en la representación puesto que muestra, de entrada, una diferencia clave en relación con otros conceptos. Según Jodelet (1984), en las representaciones sociales interviene lo social de diversas maneras: por el contexto en el cual se sitúan personas y grupos; por la comunicación que 
establecen entre ellas; por las formas de aprehensión que les brinda su bagaje cultural; por los códigos, valores e ideologías ligados a posiciones o pertenencias sociales específicas (citada en Banchs, 1984 p. 4).

También la representación social es ubicada como un constructo teórico intermedio entre lo psicológico y los social. Sin embargo, no es algo definido y contundente. El propio Moscovici aclara que la representación no es una mediadora sino un proceso que hace que concepto y percepción de algún modo sean intercambiables porque se engendran recíprocamente. Herzlich (1979) comenta que resulta más justo decir que, elaborándose a un nivel concreto, la representación social se presenta al individuo como un dato perceptivo.

Moscovici claramente señala este carácter intermedio aparente de la representación social cuando dice que ocupa una posición intermedia entre el concepto que abstrae el sentido de lo real y la imagen que reproduce lo real. Las percepciones y los conceptos son productos, modos de conocer derivados de lo icónico y de lo simbólico respectivamente. En consecuencia, se expresa esta relación como de interacción social:

Es bajo la forma de representaciones sociales como la interacción social influye sobre el comportamiento (o el pensamiento) de los individuos implicados en ella, y es al tratar de poner en práctica sus reglas cuando la sociedad forja las relaciones que deberá haber entre sus miembros individuales (Moscovici, 1979 p. 69).

La representación social es una teoría natural que integra conceptos cognitivos distintos como la actitud, la opinión, la imagen, el estereotipo, la creencia, etc., de forma que no sea una mera suma de partes o aglomeración acrítica de conceptos. Definidas las representaciones sociales como una forma de conocimiento de sentido común, estructural y funcionalmente se distinguen de otras nociones cognitivas. Con la intención de clarificar dichas diferencias, se muestran las definiciones de cada concepto cognitivo en su limitación, siguiendo de nueva cuenta a Banchs (1984):

La actitud. Uno de los componentes (junto con la información y el campo de representación) de toda representación social; es la orientación global positiva o negativa de una representación.

La opinión. Para Moscovici la opinión es una fórmula a través de la cual el individuo fija su posición frente a objetos sociales cuyo interés es compartido por el grupo.

Los estereotipos. Son categorías de atributos específicos a un grupo o género que se caracterizan por su rigidez. Las representaciones sociales, por el contrario, se distinguen por su dinamismo (aunque tienen una estructura o núcleo figurativo relativamente estable).

La percepción social. El término no se refiere a las características físicas observables sino a rasgos que la persona le atribuye al blanco de su percepción. La percepción es descrita como una instancia mediadora entre el estímulo y el objeto exterior y el concepto que de él nos hacemos. La representación social no es una intermediaria sino un proceso que hace que concepto y percepción sean intercambiables puesto que se engendran recíprocamente.

La imagen. Es el concepto que suele utilizarse más como sinónimo de representación social. Sin embargo, la representación no es un mero reflejo del mundo exterior, una huella impresa mecánicamente y anclada en la mente; no es una reproducción pasiva de un exterior en un interior, concebidos como radicalmente distintos, tal como podrían hacerlo suponer algunos usos de la palabra imagen. 
De esa diferenciación se desprende que las representaciones sociales se presentan en varias formas con mayor o menor grado de complejidad. Imágenes que condensan un conjunto de significados; sistemas de referencia interpretativa y que dan sentido a lo inesperado; categorías para clasificar circunstancias, fenómenos, individuos; teorías naturales que explican la realidad cotidiana. Conocimiento de sentido común o bien pensamiento natural (por oposición al pensamiento científico), que se construye a partir de experiencias, informaciones, conocimientos y modelos de pensamiento recibidos y trasmitidos a través de la tradición, la educación y la comunicación social: un conocimiento socialmente elaborado y compartido.

Por otro lado, entre quienes se han propuesto analizar la teoría de las representaciones sociales haciendo distinciones con respecto a la cognición social, está Darío Páez, quien hace una caracterización de las representaciones sociales a nivel de estilo de presentación de sus contenidos. Las representaciones sociales muestran :

1) Una especie de formalismo; un empleo sistemático de estereotipos lingüísticos e intelectuales (clichés, juicios, etc.). 2) La conclusión, ya conocida y definida normativamente a partir de las relaciones grupales, prima sobre el resto del razonamiento. 3) Un tipo de causalidad fenoménica simple y mixta caracteriza también a la representación social a un nivel formal. 4) La base del funcionamiento cognitivo anteriormente descrito es el razonamiento por analogía y con economía de medios. 5) A nivel de contenido las representaciones sociales se caracterizan por ser: una actitud hacia el objeto, un conjunto de conocimientos sobre este objeto social, y una serie de temas organizados jerárquicamente en un campo de representaciones sociales. 6) Por último, el lenguaje de la representación social retoma de los discursos filosóficos (ideológico y científico) algunas palabras y conceptos. (cfr. Páez, 1987 pp. 303-306).

\section{Nuevos rumbos en las investigaciones de Serge Moscovici}

En sus investigaciones acerca del psicoanálisis en Francia, Moscovici mostró interés por el sentido común, su conformación a partir de una ciencia y lo que se ha denominado pensamiento profano y epistemología popular. Había contemplado también investigar al marxismo en condiciones similares a como lo hizo con el psicoanálisis, suponiendo que las teorías económicas y políticas (como el marxismo) provocaban repercusiones sociales suficientemente ricas como para merecer la exploración. Trataba de complementar lo que había realizado con una teoría científica (el psicoanálisis). Según dice Farr (1983), es hasta los años ochenta cuando Moscovici se planteó nuevamente la idea de investigar la representación social del marxismo en la Francia contemporánea. Actualmente y luego del derrumbe del llamado "socialismo real", no se tiene conocimiento sobre publicación de resultados al respecto.

A lo largo de las últimas décadas, Moscovici ha trabajado en distintas líneas de investigación con aparente desinterés del tema de las representaciones sociales tal cual las ideó. Esta situación permitiría cuestionar si el modelo de las representaciones sociales sigue siendo la punta de lanza de la escuela de Moscovici, cosa que parece no ser ya tan contundente. Digamos mejor que sus derivaciones van desde el intento de dar cuerpo a la visión de Gabriel Tarde sobre la Psicología social como "estudio comparativo de conversaciones", hasta el fenómeno de la influencia social y la Psicología de las minorías activas. A Moscovici le interesan -dice Farr (1983)- los mecanismos por los que las ideas y pensamientos de un individuo llegan a influir sobre el pensamiento de la mayoría de los demás: la influencia minoritaria. Es decir, la forma en que unos pocos individuos muy creativos 
llegan a influir sobre la opinión pública e inclusive a conformarla. Estudios que apuntan hacia lo que es la ideología y el poder político.

Al respecto Moscovici ha hecho interesantes hallazgos en contraste con las clásicas afirmaciones de la influencia social, la contaminación y la sugestión a través de los medios de información. Moscovici habla de una "rebelión de las minorías" relacionada con la elevación general del nivel de intrucción y con la importancia de las escuelas; con la consciencia social facilitada por las comunicaciones y el crecimiento de lo individual o minoritario como reacción a la masificación social consecuencia de la planeación centralizada y racional. Señala Serge Moscovici:

Hoy en día, las minorías son un componente normal de la vida social. Los estudiosos deberían mirar el mundo desde el punto de vista de las minorías y ya no exclusivamente desde el punto de vista de las mayorías de las masas unitarias, como lo han hecho hasta ahora (Moscovici, 1980 p. 690).

Esto significa para Moscovici que la Psicología de las masas surgida en Europa bajo ciertas condiciones, no puede explicar con precisión los fenómenos de las minorías que han surgido en las últimas décadas. Moscovici busca comprender esta influencia de la minoría, distinguiendo varias condiciones:

a) representa una postura desviante o prohibida que es socialmente conveniente en cierto momento

b) puede provocar un conflicto, aunque la mayoría evite o rechace dicha crisis de cambio;

c) como la minoría muestra una ausencia de compromiso tácito su negativa a ceder genera que el conflicto sea resuelto sólo a través de una concesión de la mayoría;

d) el éxito de la influencia minoritaria se cifra especialmente en estilos de comportamiento. Se persuade más por el comportamiento y la convicción sobre un punto de vista, que por el hecho de representar a un gran número de personas, ser especialista o gozar de prestigio.

La influencia de la minoría desfasa la actitud de las mayorías: quizá se maneje un mensaje dictado por el consenso, pero las opiniones asociadas al mismo -lo subjetivo, la intimidad del individuo- serán las más moldeadas por la influencia de la minoría a través de la comunicación interpersonal y, más precisamente, de las conversaciones: modalidad de la comunicación social cuya influencia es igualmente capital pero que no ha recibido, ni de lejos, la misma atención que los medios de comunicación de masas (cfr. Ibáñez, 1988).

A estos rumbos teóricos que Moscovici ha enfilado después de su estudio sobre las representaciones sociales, debe incluirse lo que ha visto en perspectiva: la verdadera reconstitución de una Psicología colectiva entendida como una Psicología de las masas, de la muchedumbre, del comportamiento colectivo, de las comunicaciones de masas, de los estilos de comportamiento, de la "conversión", de la "criptomnesia social", entre otros temas; que se dejaron hace tiempo para la sociología y para la antropología. Paralelamente, preludia el nacimiento de tendencias psicológicas fuera de la especialidad propiamente dicha y un "mestizaje metodológico" entre la experiencia y la observación: la hermenéutica. 


\section{Representaciones sociales: Ciencia e ideología}

Las representaciones sociales aparecen en las sociedades modernas en donde el conocimiento está continuamente dinamizado por las informaciones que circulan bastamente y que exigen ser consideradas como guías para la vida cotidiana.

A diferencia de los mitos, las representaciones sociales no tienen la posibilidad de asentarse y solidificarse para convertirse en tradiciones ya que los medios de información de masas exigen el cambio continuo de conocimientos y la existencia de un receptor típico de nuestro tiempo al que Moscovici llama el *sabio aficionado o amateurt. Éste, es el aficionado consumidor de ideas científicas ya formuladas y que convierte en sentido común cuanta información recibe: como forma desacralizada y vital de conocimiento científico.

Además de distinguirse de la ciencia, el conocimiento de sentido común tiene rasgos que lo diferencian de la ideología. Apunta Moscovici:

La ciencia se preocupa por controlar la naturaleza o por decir la verdad sobre ella; (la ideología) se esfuerza más bien por proporcionar un sistema general de objetivos o por justificar los actos de un grupo humano. Subsecuentemente reclaman conductas y comunicaciones adecuadas (Moscovici, 1979 p. 52).

Significa entonces que la representación social contribuye exclusivamente al proceso de formación de conductas y a la orientación de las comunicaciones. Resolver problemas, dar forma a las interacciones sociales, proporcionar un patrón de conductas son motivos para constituir una representación y separarse de lo que es la ciencia y lo que es la ideología.

Por otra parte, la ciencia se liga ideológicamente con el poder de "quien sabe", y el sentido común es vilipendiado porque significa la vulgarización y la caída de ese saber. Tal menosprecio se explica por la desigual valoración de los conocimientos: por un lado la ciencia y por el otro el sentido común. En efecto, se olvida que así como el conocimiento científico es incorporado al lenguaje de la vida cotidiana constituyendo una auténtica red de opiniones, válida para la convivencia social, el conocimiento popular de sentido común aporta -a la larga, quizá- los sustentos que la ciencia requiere para ser ideada.

Indagando sobre la doble dirección de flujo dada en este proceso, Moscovici y Hewstone plantean al sentido común como una especie de conocimiento de menor jerarquía científica (aunque no por ello menos complejo), y que suele aparecer en dos formas:

Primero, en tanto que cuerpo de conocimientos producido de forma espontánea por los miembros de un grupo, basado en la tradición y el consenso. Siendo un conocimiento de primera mano, es un terreno donde nace y prospera la ciencia. Segundo, en tanto que suma de imágenes mentales y de lazos de origen científico, consumidos y transformados para servir en la vida cotidiana (Moscovici y Hewstone, 1984 p. 685).

Cuando el sentido común ha sido estructurado en forma tal que el rigor lo pueda hacer ciencia, se producen desequilibrios y tomas de posición contradictorias que se traducen en el lenguaje. El mismo vocabulario tiende a asimilarse al nuevo implicando reemplazo y desmantelamiento simultáneos de las cadenas lingüísticas existentes. Inversamente, la formación de una representación social y su generalización entrañan la injerencia de la propia lengua en la teoría, a manera de una jerga científica que se convierte en una versión socialmente autorizada de un modo de acceso al saber y a los 
fenómenos que son inaccesibles a la colectividad. Mediante lo que Moscovici y Hewstone (1984) denominan positividad, es decir, la repetición afirmativa de una información para minimizar sus aspectos negativos y sus particulares cualidades, se facilita que circulen dentro del grupo las nociones que la representación social estructura como explicación de lo cotidiano. En este amplio dominio de la ideología, las representaciones sociales se refieren a entidades más concretas, aprehensibles cognitiva y comportamentalmente, así como a unidades de significado en las cuales se cuela mucho de lo ideológico.

Para Darío Páez (1987) las representaciones sociales son la forma presistematizada o vulgarizada, en el discurso del sentido común, de las ideologías. Son un auténtico discurso ideológico no institucionalizado: la ideología es el discurso social de la legitimación de la hegemonía sustentada en la división del trabajo y en el lenguaje. Además, la ideología no se concreta a un conjunto de representaciones, sino que implica una serie de instituciones productoras del discurso de legitimación y de las prácticas sociales que lo concretizan.

De esta manera, llegamos a la consideración de la ideología y de las representaciones sociales como aspectos que la Psicología social debe examinar en sus funciones. Como lo ha señalado Martín-Baró (1983), analizar la acción humana en cuanto ideológica, es decir, en cuanto determinada por factores sociales vinculados a los intereses de clase grupal. Acción en la que se pretende que el sujeto tome conciencia de esos determinismos y pueda asumirlos (aceptándolos o rechazándolos) mediante una praxis consecuente.

Según el mismo Martín-Baró (1983), resulta significativo constatar que la Psicología social se ha dispuesto bajo la óptica de la ideología imperante al atender a procesos como la sumisión, la obediencia y el conformismo, e investigar muy excepcionalmente sobre la desobediencia, la inconformidad y el cambio social.

Cuando Moscovici complementa su teoría de las representaciones sociales con sus trabajos acerca de las minorías activas y la influencia social, da dimensión al descubrimiento de la ideología que subyace y domina, al sentido común como una forma de pensamiento social que puede resultar valiosa para el análisis, descripción y desmantelamiento de la ideología como discurso de dominación. En suma, hacer una auténtica Psicología política.

Consideramos que un primer acercamiento sería dado si se valorara el sentido común mismo, ya que pareciera ser una máscara pública, idea o coartada a la que se aspira o tras la que se suele esconder. No se trata de quedar en el simple reconocimiento del sentido común, ni en su elevación a categoría moral de comunicación popular o "de la gente". Ni se trata tampoco de dibujar las supuestas imágenes de las representaciones, apelando a una tecnología de investigación que desprecia el espíritu metodológico que Moscovici estableció y que la mayoría de sus epígonos conocidos por nosotros parece ignorar o al menos enfocarlo con el punto ciego de la retina. Lo que sí conviene es descubrir su trasfondo para detectar las ideologías que lo utilizan como explicaciones acríticas de la realidad. Tal como lo sugiere Fernández Christlieb (s.f.), a la sombra del sentido común existe la colectividad efervescente en privado. Es decir, partiendo de esta hipótesis o creencia puede argumentarse, junto con Fernández Christlieb, que "la Psicología colectiva debe dedicarse a romper el sentido común". 


\section{CONSIDERACIONES FINALES}

Investigar la teoría de las representaciones sociales propuesta por Serge Moscovici nos ha permitido conocer diferentes opiniones así como vislumbrar la pluralidad de áreas de las ciencias sociales que contribuyen a la comprensión del objeto esencial de la teoría: el sentido común, su comunicación y la construcción de la realidad cotidiana. Sobre éstos hallazgos básicos, podemos comentar algunas consideraciones pertinentes.

Las representaciones sociales son características de nuestra época principalmente por la abundancia de las informaciones circulantes, por su vigencia relativamente breve como opiniones y la consecuente improbabilidad de estructurar tantas ideas en un esquema teórico permanente. Es decir, el sentido común se impone como la explicación más extendida y determinante de las relaciones de intercambio social. Por ello, su análisis y desconstrucción se presenta como una vía de abordaje deseable y pertinente.

La distinción tajante entre ciencia y sentido común se hace cada vez menos sostenible. La dinámica de influencia entre una y otro resulta tema inevitable de análisis y estudio. La estrategia metodológica podría seguir una postura de cuestionamiento de la expertez y del supuesto saber para ir a la observación de la vida cotidiana.

Bajo esta perspectiva teórica pueden ser analizados una vasta gama de fenómenos: percepción social, mecanismos de comunicación, función de la ideología en la formación del sentido común y en la determinación de lo que es o no científico; las formas de pensamiento y su aplicación, las creencias y los mitos, los criterios sobre la normalidad en términos consensuales; la conformación de la opinión pública y la influencia social. Fenómenos que, dicho sea de paso, no son exclusivos de la Psicología social y que ahora más que nunca se imponen como materia de análisis de cualquier estudioso que tenga en la curiosidad y en la duda sistemática sus asideros preferidos.

Complementa, e inclusive integra, distintos conceptos cognitivos y sociales que han sido tratados individualmente y a veces intercambiados o confundidos, entre otras razones por la parcelación metodológica y disciplinar en las ciencias sociales. Sin embargo, debe reconocerse que este es uno de los puntos de conflicto que exhibe el modelo de las representaciones sociales y que pocos de sus seguidores se preocupan por discutir.

La investigación de las representaciones sociales encierra posibles dificultades metodológicas, principalmente por la necesidad de englobar sus dimensiones en un solo y relacionado corpus. Ni la actitud, ni la información y ni el campo de representación por separado nos aclaran el concepto de la representación social. Paralelamente, las vías metodológicas tradicionales no resultan ser las más idóneas para el tratamiento de esta teoría por su énfasis en los aspectos cuantitativos y menos en los interpretativos. Hecho que, en ocasiones desafortunadas, es esgrimido a contrapelo por algunos de los mismos investigadores inscritos en el modelo moscoviciano.

Algo que resulta característico de la teoría es su naturaleza integral. Es decir, que con fines didácticos los estudiosos esquematizan distinguiendo aspectos que sólo en su dinámica general se explican. Moscovici mismo reafirma en su exposición el carácter global y la describe evitando todo lo posible su incoherencia mediante una cuidadosa redacción.

Es posible observar en forma social y de producción cultural el desarrollo cognoscitivo que Piaget definiera en la ontogenia y, sobre todo, contemplar la convivencia de distintos niveles cognitivos 
interactuando. El sentido común sería ese lenguaje homogéneo que aglutinaría a inteligencias dispares. La advertencia respecto a no mitificar el sentido común sino ponderarlo y desarticularlo para enriquecer la comprensión de la colectividad, viene muy oportuna.

Este modelo ha sido considerado por algunos psicólogos sociales latinoamericanos como apropiado y útil en la indagación de los fenómenos de opresión y en las maneras de desenmascarar la ideología dominante impuesta en forma de sentido común. Desafortunadamente, no es una teoría suficientemente extendida sino que es casi desconocida, es muy poco empleada y la mayoría de veces deformada o tenida como la única opción vanguardista, lo cual dista mucho de ser cierto.

Epistemológicamente, la teoría se inscribe dentro de la tradición que enfatiza la interacción entre sujeto y objeto de conocimiento. La relación de influencia recíproca y sus mecanismos de construcción de la realidad son los rasgos legítimos para su análisis. Por esta razón, la teoría de las representaciones sociales de Serge Moscovici está emparentada con la sociología fenomenológica del conocimiento, con el interaccionismo simbólico y la teoría crítica de Habermas, con la etnometodología, la historia de las mentalidades, con los métodos de análisis interpretativo del discurso social.

Finalmente, vale considerar que el modelo de las representaciones sociales de Moscovici ha generado una de las vertientes modernas de investigación psicosocial y que todavía trabaja por convertirse en una tradición de investigación al igual que movimientos como el construccionismo social o aquel englobado bajo el rubro de Psicología social crítica. Se trata de una de las propuestas que permiten el diálogo permanente con las disciplinas de interpretación de la vida cotidiana y del sentido común, es decir, de la cultura urbana.

\section{BIBLIOGRAFIA}

Acosta, Karía Teresa. La noción de representación social: su estudio en la Psicología social.UNAM mecanografiado s/f.

Banchs, María Auxiliadora. "Efectos del contacto con la cultura francesa sobre la representación social del venezolano" En: Interamerican Journal of Psvchology._1982, Vol. 2, pp. 111-120.

"Las representaciones sociales: sugerencias sobre una alternativa teórica y un rol posible para los psicólogos sociales en Latinoamérica" En: Bernardo Jiménez (compilador) Aportes críticos a la Psicología social en Latinoamérica.Guadalajara: Universidad de Guadalajara 1990. pp. 183-217.

Berger, Peter y Luckman, Thomas (1967) La construcción social de la realidad. Buenos Aires: Amorrortu, 1986.

Danzinger, Kurt. "Orígenes y principios básicos de la Völkerpsychologie de Wundt". En Graciela de la Rosa Cedillo, Héctor Meza Aguilar y José Joel Vázquez Ortega (compiladores) Historia de la Psicología Social Vol. I. Universidad Autónoma Metropolitana, 1988, pp. 131-147

Di Giacomo,J.P. "Teoría y método de análisis de las representaciones sociales" En : Darío Páez et al. Pensamiento, individuo y sociedad. Cognición y representación social. Madrid: Fundamentos, 1989. pp. 278-295. 
Dobles, Ignacio et al. Representación sobre el endeudamiento externo en estudiantes universitarios costarricenses. Universidad de Costa Rica: mecanografiado, s/f.

Donolo, Carlo (1981) “Sociología” En: La cultura del 900. México: Siglo XXI, 1985.

Durkheim, Emile (1895) Las reglas de método sociológico. México: Fondo de Cultura Económica, 1986.

Farr, Robert M. "Escuelas europeas de Psicología social: la investigación de representaciones sociales en Francia" En: Revista Mexicana de Sociología Año XLV Vol. XLV Instituto de Investigaciones Sociales/UNAM , pp 641-657.

Farr, Robert M. "Las representaciones sociales" En: Serge Moscovici (compilador) Psicología Social II Barcelona: Paidós, 1986 pp. 495-506.

Fernández Christlieb, Pablo. La psicosociología: un provecto de Psicología social. Laboratorio de Psicología Social, UNAM. mecanografiado. 1984.

Fernández Christlieb, Pablo "Reintroducción a la Psicología colectiva" En: P. Fernández, G. Domingo, F. Pérez Cota y otros. El ensayo de la Psicología colectiva. UNAM: mecanografiado, s/f.

Herzlich, Claudine. "La representación social: sentido del concepto" En: Serge Moscovici (compilador) Introducción a la Psicología social. Barcelona: Planeta, 1979.

Joas, Hans (1987) "Interaccionismo simbólico" En: A. Giddens, J. Turner y otros. (compiladores) La teoría social hoy. Madrid: Alianza.

Jodelet, Dense "La representación social: fenómenos, concepto y teoría. En Serge Moscovici (compilador). Psicología Social II. Barcelona: Paidós, 1984, pp. 469-493.

Martín-Baró, Ignacio (1983) Acción e ideología. San Salvador: Universidad Centroamericana, 1985.

Moscovici, Serge (1961) El psicoanálisis, su imagen y su público. Buenos Aires: Huemul, 1979.

Páez, Darío. "Características, funciones y proceso de formación de las representaciones sociales" En: Darío Páez y colaboradores: Pensamiento, individuo y sociedad. Cognición y representación social. Madrid: Fundamentos, 1987, pp. 297-317.

\section{Referencia}

Mora, Martín (2002). La teoría de las representaciones sociales de Serge Moscovici. Athenea Digital, 2. Disponible en http://blues.uab.es/athenea/num2/Mora.pdf 